九州大学学術情報リポジトリ

Kyushu University Institutional Repository

\title{
Estimating the Agricultural Water Productivity of the Yellow River Basin Based on Remote Sensing Data
}

Wang, Guoqiang

College of Water sciences, Beijing Normal University

Xue, Baolin

Laboratory of Forest Ecosystem Management, Division of, Department of Forest \& Forest Products Sciences, Graduate School of Bioresearch and Bioenvironmental Sciences, Kyushu University

Yu, Jingshan

College of Water sciences, Beijing Normal University

Otsuki, Kyoichi

Laboratory of Ecohydrology, Division of Forest Sciences, Department of Agro-environmental

Sciences, Faculty of Agriculture, Kyushu University

https://doi.org/10.5109/19543

出版情報 : 九州大学大学院農学研究院紀要. 56 (1)，pp. 149-156，2011-02. 九州大学大学院農学研究院 バージョン：

権利関係 : 


\title{
Estimating the Agricultural Water Productivity of the Yellow River Basin Based on Remote Sensing Data
}

\section{Guoqiang WANG ${ }^{1}$, Baolin $\mathrm{XUE}^{2}$, Jingshan $\mathrm{YU}^{1 *}$ and Kyoichi OTSUKI ${ }^{3}$}

\author{
Laboratory of Ecohydrology, Division of Forest Sciences, Department of Agro-environmental Sciences, \\ Faculty of Agriculture, Kyushu University, Fukuoka 811-2415, Japan \\ (Received October 27, 2010 and accepted November 8, 2010)
}

\begin{abstract}
Water shortage for agricultural water use is a major problem in the Yellow River basin. This research use NDVI value, meteorological data, supervised classification in remote sensing image and actual statistical data to estimate and verify the wheat and maize distribution and the relevant crop water productivity values in the Yellow River basin. The validation of the method is performed by comparing the results with the distribution of CIESIN statistic data for 1990. To obtain the accurate crop water productivity, the study used and compared two methods for calculating the total crop water productivity. The first one is to sum the crop water productivity calculated by multiplying the crop water requirement per unit area and the estimated planting total area of crops in the basin. The second one is to sum the crop water productivity calculated for each province. The research found that the remote sensing data could efficiently improve the accuracy in estimating the crop water productivity.
\end{abstract}

Keywords: NDVI; remote sensing classification; Yellow River; crop water productivity

\section{INTRODUCTION}

The Yellow River is the second largest river in China and flows across nine provinces in the Northwest and North China, covering an area of about $7.93 \times 10^{5} \mathrm{~km}^{2}$ (see Fig. 1). In recent years, the water scarcity in the Yellow River basin has been getting worse because of human activity and climate change (Fu et al., 2004; Liu and Xia, 2004; Xia et al., 2004; Zheng et al., 2007). The agricultural water uses accounted for about $90 \%$ of all water consumption in 1999 and 2000 (see Table 1). Irrigation for wheat and maize has the largest share of the total water use in the basin. Thus, how to estimate the crop water productivity is necessary for water management in the Yellow River basin.

Many methods have been used to estimate the crop water productivity (e.g. lysimeters, eddy correlation, Bowen ration). Zhang and Kang (2007) used the Bowen ratio energy balance method to estimate the seasonal crop water productivity in a vineyard in an arid region with accurate results. Mo and Liu (2001) used eddy correlation measurement, and Lei and Yang (2010) used physical models to estimate the crop water productivity, and

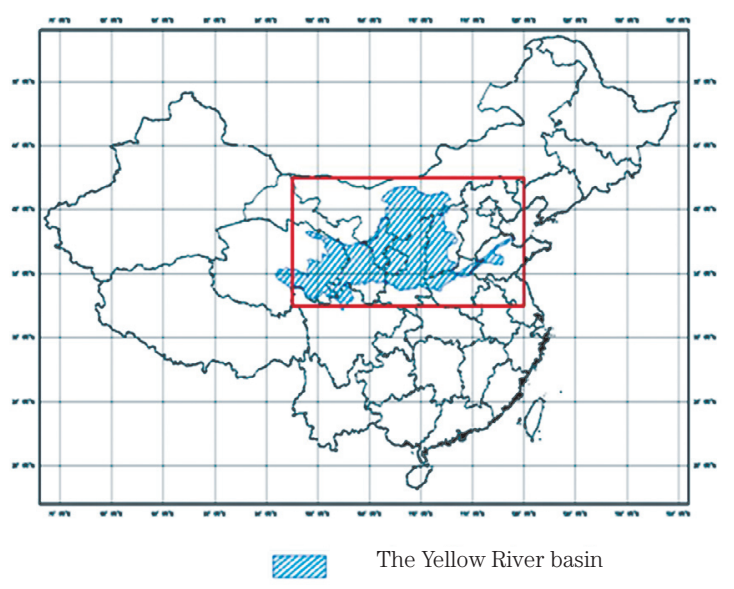

Fig. 1. Map of the Yellow River basin.

Table 1. Water consumptions in the Yellow River basin $\left(10^{9} \mathrm{~m}^{3}\right)$ (YRCC, 1999 and 2000)

\begin{tabular}{lcccc}
\hline Water consumptions & $\begin{array}{c}\text { Total water } \\
\text { consumption }\end{array}$ & $\begin{array}{c}\text { Agricultural water } \\
\text { consumption }\end{array}$ & $\begin{array}{c}\text { Industrial water } \\
\text { consumption }\end{array}$ & $\begin{array}{c}\text { Household water } \\
\text { consumption }\end{array}$ \\
\hline Surface water in 1999 & 298.74 & $273.26(91.5 \%)$ & $16.14(5.4 \%)$ & $5.26(1.8 \%)$ \\
Groundwater in 1999 & 94.00 & $64.74(68.9 \%)$ & $13.74(14.6 \%)$ & $4.37(4.6 \%)$ \\
Surface water in2000 & 272.32 & $239.29(87.9 \%)$ & $20.57(7.6 \%)$ & $8.76(3.2 \%)$ \\
Groundwater in 2000 & 93.57 & $64.15(68.6 \%)$ & $13.14(14.0 \%)$ & $4.46(4.8 \%)$ \\
\hline
\end{tabular}

${ }^{1}$ College of Water sciences, Beijing Normal University, Xinjiekouwai Street 19, Beijing 100875, China

${ }^{2}$ Laboratory of Forest Ecosystem Management, Division of, Department of Forest \& Forest Products Sciences, Graduate School of Bioresearch and Bioenvironmental Sciences, Kyushu University, Fukuoka 811-2415, Japan

${ }^{3}$ Laboratory of Ecohydrology, Division of Forest Sciences, Department of Agro-environmental Sciences, Faculty of Agriculture, Kyushu University, Fukuoka 811-2415, Japan

* Corresponding author (E-mail: jingshan@bnu.edu.cn) 
obtained the acceptable results. However, their methods are difficult to use due to too many parameters in the models or lack of regional representativeness by the measurements. In recent years, remote sensing (RS) has been proved to be a useful method for estimating crop water productivity with acceptable confidences (Bastiaanssen et al., 1998a; Bastiaanssen et al., 1998b; Li et al., 2008). In this study, the RS based method is used for calculating the crop water productivities of wheat and maize in the Yellow River basin. The objectives of the research are 1) to investigate the land cover patterns by using RS data and then 2) to estimate the crop water productivity in these identified areas.

\section{MATERIALS AND METHOD}

\section{Land cover pattern}

The land cover patterns were investigated through three approaches: 1) NDVI, 2) NDVI and meteorological data and 3) NDVI, meteorological data and supervised classification. Under each scenario, the land cover patterns were calculated using the grid method.

In our research, the resolution of the $\mathrm{RS}$ data was 30-second. Thus, to calculate the metric distance for each second, the following formula was used:

$$
\begin{aligned}
& \operatorname{Lat}(1 \mathrm{sec})=\frac{\pi}{64800} \times \frac{a\left(1-e^{2}\right)}{\left(1-e^{2} \sin (\phi)\right)^{\frac{3}{2}}} \\
& \operatorname{Lon}(1 \mathrm{sec})=\frac{1}{3600} \times \frac{\pi}{180} \times \frac{a \cos (\phi)}{\sqrt{1-e^{2} \sin ^{2}(\phi)}}
\end{aligned}
$$

where $\phi$ is latitude, $a$ is equatorial radius ( $a=$ $6,378,136 \mathrm{~m}), e$ is eccentricity of the earth $\left(e^{2}=\right.$ $0.006694470)$. Thus, the metric area $S\left(\mathrm{~m}^{2}\right)$ for one grid can be calculated from:

$$
S=\frac{(\operatorname{Lon}(p+1)+\operatorname{Lon}(p))}{2} \times \frac{\operatorname{Lat}(p+1)+\operatorname{Lat}(p)}{2}
$$

where $p$ represents the $p$ th grid.

\section{Remote sensing and meteorological data}

The SPOT VEGETATION data was used for calculating Normalized Difference Vegetation Index (NDVI) under supervised classification. The VEGETATION includes new sensors for vegetation detection, developed by France, the European Union, Belgium, Italy and Sweden. They were loaded in SPOT-4 satellite launched in March 1998 and the SPOT-5 satellite launched in May 2002. The VEGETATION sensors are more specific for moisture content, chlorophyll absorption, structure characteristics, and spectral measurements (Guo et al., 2009). In this study, the VEGETATION data recorded from 1999 to 2000 were used to calculate the total crop water productivities of wheat and maize.

For supervised classification, two sampling points were selected in the Yellow River basin, which can represent the general land cover patterns in the regions. The sampling points are located in Henan province and Anhui province respectively. The observation periods were from 1998 to 2001. The meteorological data were collected from the Chinese statistical yearbook (National Bureau of Statistics, 1994 to 2000). The RS data used for representing the land cover patterns in the Yellow River basin (see Fig. 2) were collected from Center for International Earth Science Information Network in 1990 (CIESIN, 1990), which are more detailed compared to the other RS data in this region (e.g. JAWF, Frolking et al., 2000). The land cover pattern in the Yellow River basin have kept relatively stable since 1980s (Shao and Yan, 2007), which indicates that RS data recorded in 1990 can be used for representing the land cover pattern in the following decade.

\section{Crop water productivity}

The crop water productivity per unit area $W_{u}\left(\mathrm{~m}^{3} / \mathrm{ha}\right)$ can be calculated using crop water productivity per unit yield $U_{w}\left(\mathrm{~m}^{3} / \mathrm{t}\right)$ and yield per unit area $U_{m}(\mathrm{t} / \mathrm{ha})$,

$$
W_{u}=U_{w} \times U_{m}
$$

The $U_{w}$ values for wheat and maize were set to 2000 $\left(\mathrm{m}^{3} / \mathrm{t}\right)$ and $1900\left(\mathrm{~m}^{3} / \mathrm{t}\right)$ respectively by referring to the research works done by Oki et al. (2002).

The provincial crop water productivity $W_{u}^{i}\left(\mathrm{~m}^{3} / \mathrm{ha}\right)$ was calculated as follows:

$$
W_{u}^{i}=U_{w} \times U_{m}^{i}
$$

where $U_{m}^{i}$ (t/ha) is the provincial yield per unit are mass and $i$ represents the $i$ th province in the Yellow River
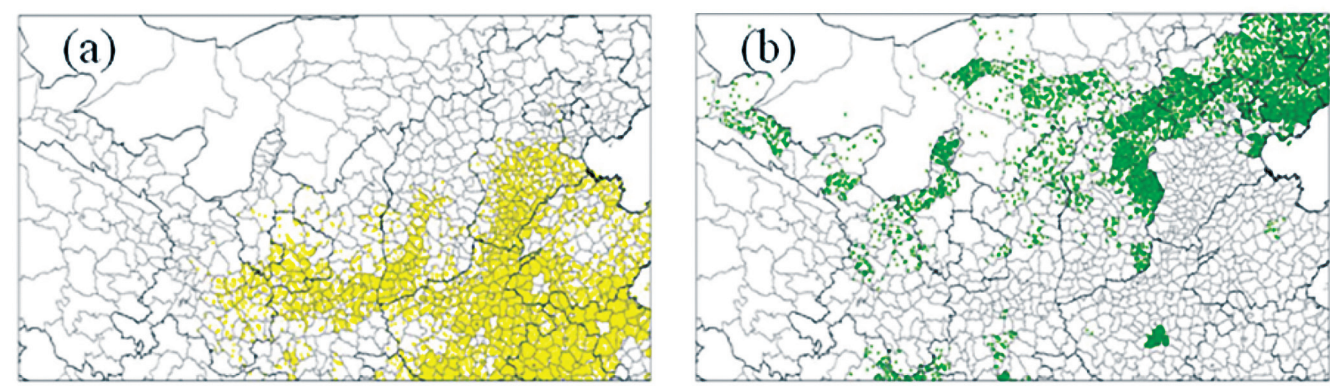

Fig. 2. Spatial distributions of wheat (a) and maize (b) identified using CIESIN data in 1990. 
basin. The $U_{m}^{i}$ values for wheat and maize were determined using the China Statistical Yearbook (1995-1998) data.

The average crop water productivity $W_{u}^{*}$ was calculated using the area weighted average yield per unit area $U_{m}^{*}$

$$
\begin{aligned}
W_{u}^{*} & =U_{w} \times U_{m}^{*} \\
U_{u}^{*} & =\sum_{i=1}^{n}\left(U_{m}^{i} \cdot \frac{A_{i}}{A^{*}}\right)
\end{aligned}
$$

where $A_{i}$ is the crop area of $i$ th province, $A^{*}$ is the total crop area, and $n$ is the number of provinces in the Yellow River basin. Table 2 shows the $U_{m}^{*}$ values for wheat and maize from 1995 to 1998 . The average $W_{u}^{*}$ values calculated for wheat and maize were $7640\left(\mathrm{~m}^{3} / \mathrm{ha}\right)$ and 9462 $\left(\mathrm{m}^{3} / \mathrm{ha}\right)$, respectively.

Table 2. $U_{m}^{*}$ values calculated using the China Statistical Yearbook (1995-1998)

\begin{tabular}{cccccc}
\hline Year & 1995 & 1996 & 1997 & 1998 & Average \\
\hline wheat & 3.62 & 3.76 & 4.06 & 3.85 & 3.82 \\
maize & 4.91 & 5.15 & 4.51 & 5.35 & 4.98 \\
\hline
\end{tabular}

\section{Total crop water productivity}

Two methods were used to calculate the total crop water productivities of wheat and maize. The Method-1 calculates the total crop water productivity $W\left(\mathrm{~m}^{3}\right)$ by multiplying the average crop water productivity $W_{u}^{*}$ and the total crop area $A^{*}$ identified by Approaches $1-3$.

Method-1:

$$
W=W_{u}^{*} \cdot A^{*}
$$

where $W$ is the crop water productivity $\left(\mathrm{m}^{3}\right)$.
Method-2 calculates the total crop water productivity $W$ by summing all the provincial crop water productivities calculated by multiplying the provincial $W_{u}^{i}$ and crop area $A^{i}$.

Method-2:

$$
W=\sum_{i=1}^{n}\left(W_{u}^{i} \cdot A_{i}\right)
$$

\section{RESULT AND DISCUSSION}

\section{Land cover pattern}

The land cover patterns were calculated through three approaches: 1) NDVI, 2) NDVI and meteorological data and 3) NDVI, meteorological data and supervised classification.

Approach-1: NDVI

The NDVI criterions for wheat and maize were referenced to Wan et al. (2004). The detailed values are as follows:

For wheat:

(1) NDVI is smaller than 0.7 in the middle ten days of last October;

(2) NDVI is larger than 0.5 in the middle ten days of April.

For maize:

(1) NDVI is smaller than 0.36 four months before the maximum month;

(2) NDVI is smaller than 0.19 four months after the maximum month;

(3) NDVI is larger in the three months before the maximum month than that in three months after the maximum month;

(4) NDVI is smaller than 0.22 six months after the maximum month.

According to the above conditions for wheat and maize, the spatial distributions of wheat and maize were identified (Fig. 3).
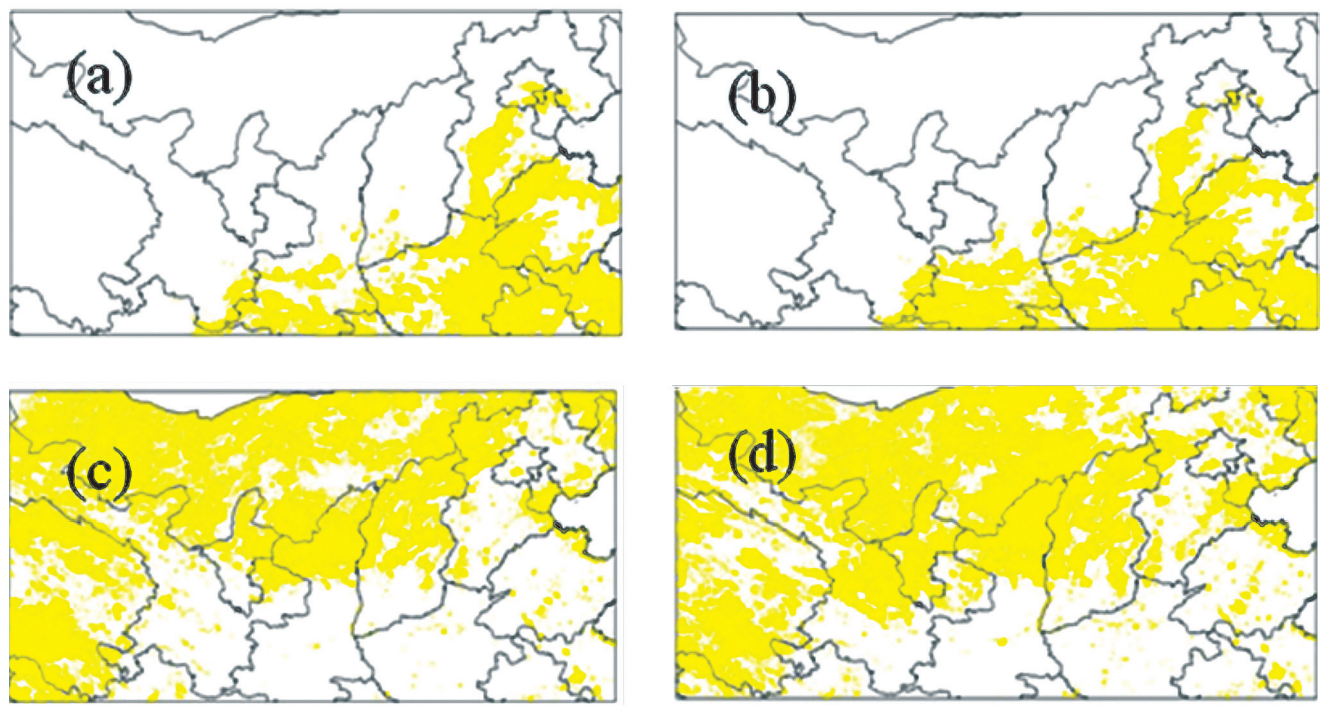

Fig. 3. Wheat and maize distribution in 1999 and 2000 calculated by Approach-1 using NDVI: (a) wheat in 1999; (b) wheat in 2000; (c) maize in 1999; (d) maize in 2000. 
The identified wheat areas (Fig. 3a,b) are similar to the reference map derived from the CIESIN data (Fig. 2a). The difference between the wheat areas identified by Approach-1 and CIESIN data is less than $25 \%$ of the total wheat area. In detail, the identified wheat area in 2000 is larger than that in 1999, especially in Shanxi province. On the other hand, the identified maize area (Fig. 3c,d), approximately the same in 1999 and 2000, are different from the reference map derived from the CIESIN data (Fig. 2b). While maize does not exist in the northern part of Inner Mongolia Autonomous Region and the western part of Qinghai province in the CIESIN data, maize was identified in these regions by Approach-1. These regions are considerably cooler than the other regions. These results imply that the meteorological condition may not affect the identification of wheat distribution, but have impacts on identifying the maize distributions.

Approach-2: NDVI and meteorological data

The meteorological data and corresponding criterions for growth of wheat and maize were used to improve the accuracy of Approach-1. The proper meteorological conditions for the growth of crops are shown in Table 3.

Based on Table 3, unsuited regions for the growth of crops were subtracted from the crop areas identified by
Approach-1. The criterions for identifying wheat and maize distributions were then revised as follows:

For wheat:

(1) NDVI is smaller than 0.7 in the middle ten days of last October;

(2) NDVI is larger than 0.5 in the middle ten days of April;

(3) The annual accumulative daily temperature (for temperature values above $8^{\circ} \mathrm{C}$ ) is larger than $2400{ }^{\circ} \mathrm{C}$, and the total precipitation is less than $900 \mathrm{~mm}$.

For maize:

(1) NDVI is smaller than 0.36 four months before the maximum month;

(2) NDVI is smaller than 0.19 four months after the maximum month;

(3) NDVI is larger in the three months before the maximum month than that in three months after the maximum month;

(4) NDVI is smaller than 0.22 six months after the maximum month;

(5) The annual accumulative daily temperature (for temperature values above $8{ }^{\circ} \mathrm{C}$ ) is larger than $2400^{\circ} \mathrm{C}$, and the total precipitation is less than $900 \mathrm{~mm}$.

According to the above conditions for wheat and maize, their spatial distributions in 1999 and 2000 were

Table 3. Proper meteorological conditions for the growth of crops

\begin{tabular}{llcc}
\hline \multicolumn{1}{c}{ Type } & \multicolumn{1}{c}{ Feature } & $\begin{array}{c}\text { Annual total daily } \\
\text { temperature above } 8^{\circ} \mathrm{C}\end{array}$ & $\begin{array}{c}\text { Annual cumulative } \\
\text { precipitation (mm) }\end{array}$ \\
\hline \multirow{2}{*}{ Best suited } & Heat (proper); Water (proper) & $3000-3800$ & $500-700$ \\
\multirow{2}{*}{ Suited } & Water (proper) & $2700-3000$ & $500-700$ \\
\multirow{2}{*}{ Slight suited } & Heat (proper) & $3000-3600$ & $400-500$ \\
& Heat (proper); Water (excess) & $3000-3600$ & $700-800$ \\
\multirow{2}{*}{ Unsuited } & Water (proper); Heat (insufficient) & $2400-3000$ & $400-700$ \\
& Water (excess) & $3000-3200$ & $>900$ \\
& Heat (insufficient) & $<2400$ & $400-800$ \\
\hline
\end{tabular}
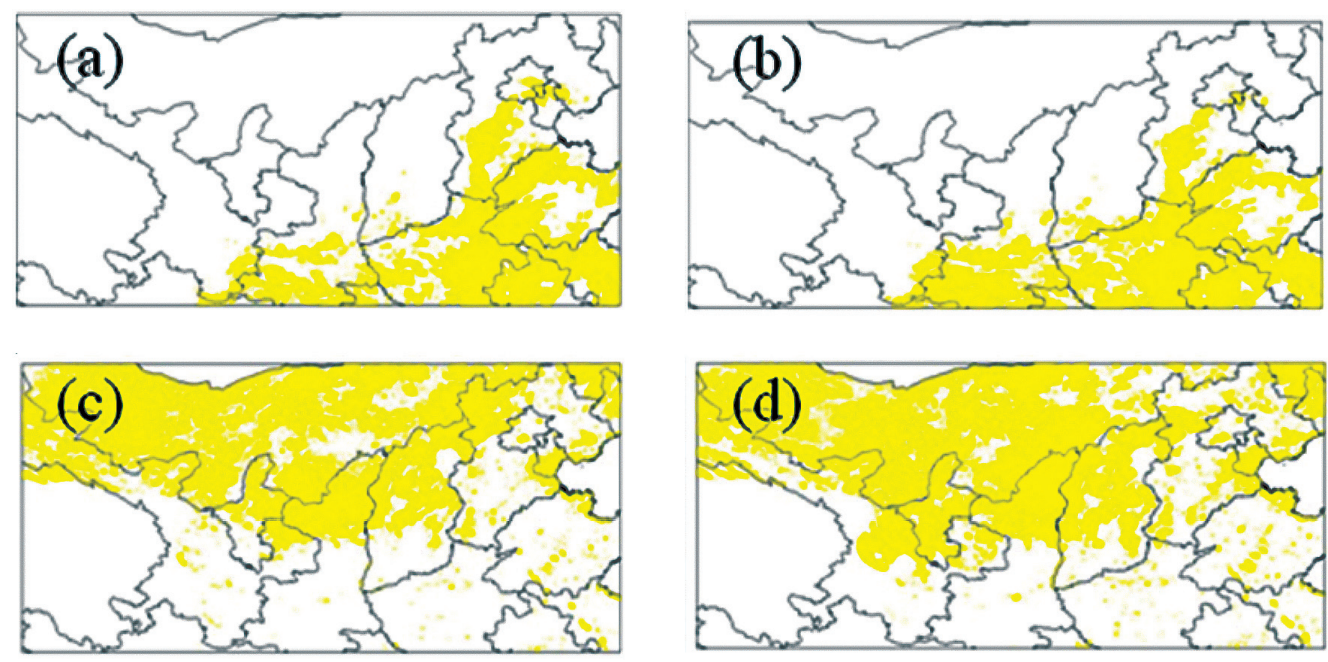

Fig. 4. Wheat and maize distribution in 1999 and 2000 calculated by Approach-2 using NDVI and meteorological data: (a) wheat in 1999; (b) wheat in 2000; (c) maize in 1999; (d) maize in 2000. 
identified (Fig. 4).

The identified wheat distribution (Fig. 4a, b) is similar to the reference map derived from the CIESIN data (Fig. 2a) in the whole Yellow River basin. There is no big difference between identified wheat distribution by Approach-1 (Fig. 3a, b) and Approach-2 (Fig. 4a, b), which confirms the implication that the NDVI is an efficient indicator of wheat distribution. Meanwhile, the inclusion of meteorological data is found to be helpful in improving the accuracy of image interpretation in some regions.

The identified maize distribution (Fig.4c, d) is similar to Fig. 3c,d with the total area decreased by about $10 \%$, which is altered by the inclusion of meteorological data. However, this result is still considerably larger than the reference map derived from the CIESIN data (Fig. 2b).

Approach-3: NDVI, meteorological data and supervised classification

The seasonal variations of NDVI at the two sampling

(b)
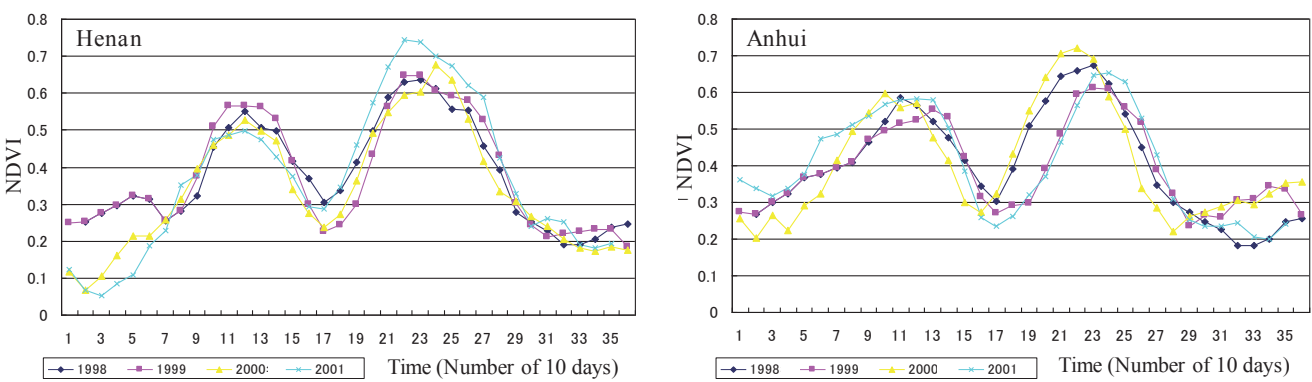

(c)

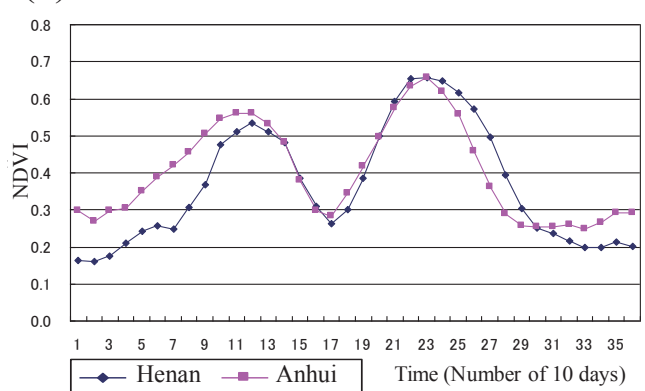

Fig. 5. NDVI values calculated at sample sites 1 (a), 2 (b) and the averaged NDVI values (c).

(a)

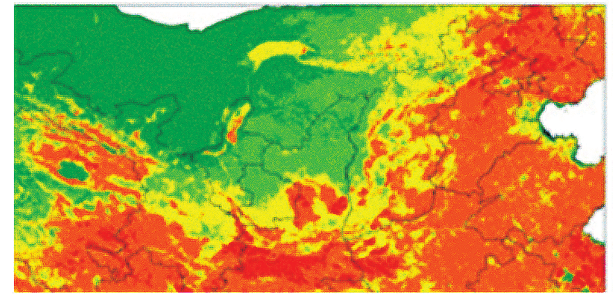

(c)

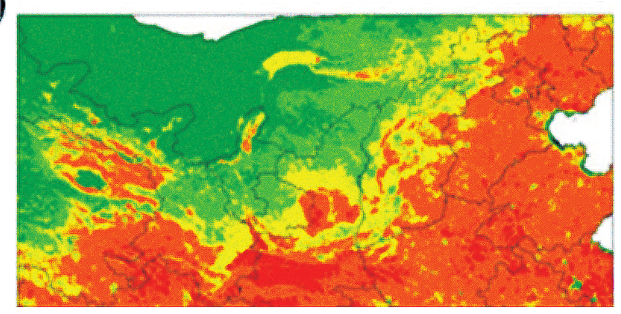

(b)

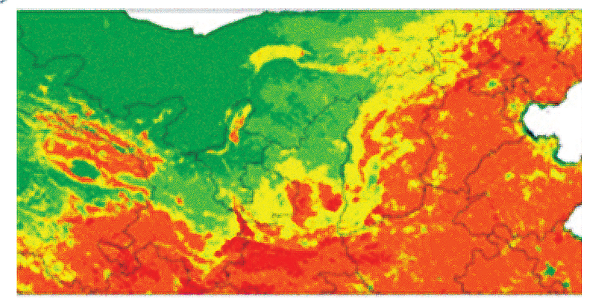

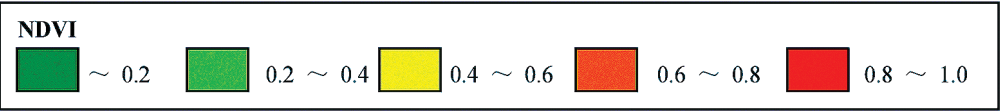

Fig. 6. Maximum NDVI for maize in 1999(a), 2000(b) and 2001(c). 
sites calculated from 1998 to 2001 are shown in Fig. 5.

The four year NDVI curves vary during winter from November to next March, while they match well in October, April, and August. October and April correspond the beginning of wheat cultivation and the peak of wheat growth respectively, whereas August when the NDVI is at a maximum corresponds the maize growing period. Therefore, the NDVIs in October and April were selected as the criteria for wheat distribution and the annual maximum NDVI was selected as the criterion for the maize distribution (see Fig. 6).

Thus, the overall criterions for wheat and maize are as follows:

For wheat:

(1) NDVI is smaller than 0.255 in the middle ten days of last October;

(2) NDVI is larger than 0.530 in the middle ten days of April;

(3) The annual accumulative daily temperature (for temperature values above $8{ }^{\circ} \mathrm{C}$ ) is larger than $2400{ }^{\circ} \mathrm{C}$, and the total precipitation is less than $900 \mathrm{~mm}$.

For maize:

(1) NDVI is smaller than 0.36 four months before the maximum month;

(2) NDVI is smaller than 0.19 four months after the maximum month;

(3) NDVI is larger in the three months before the maximum value month than that in three months after the maximum month;

(4) NDVI is smaller than 0.22 six months after the maximum month;
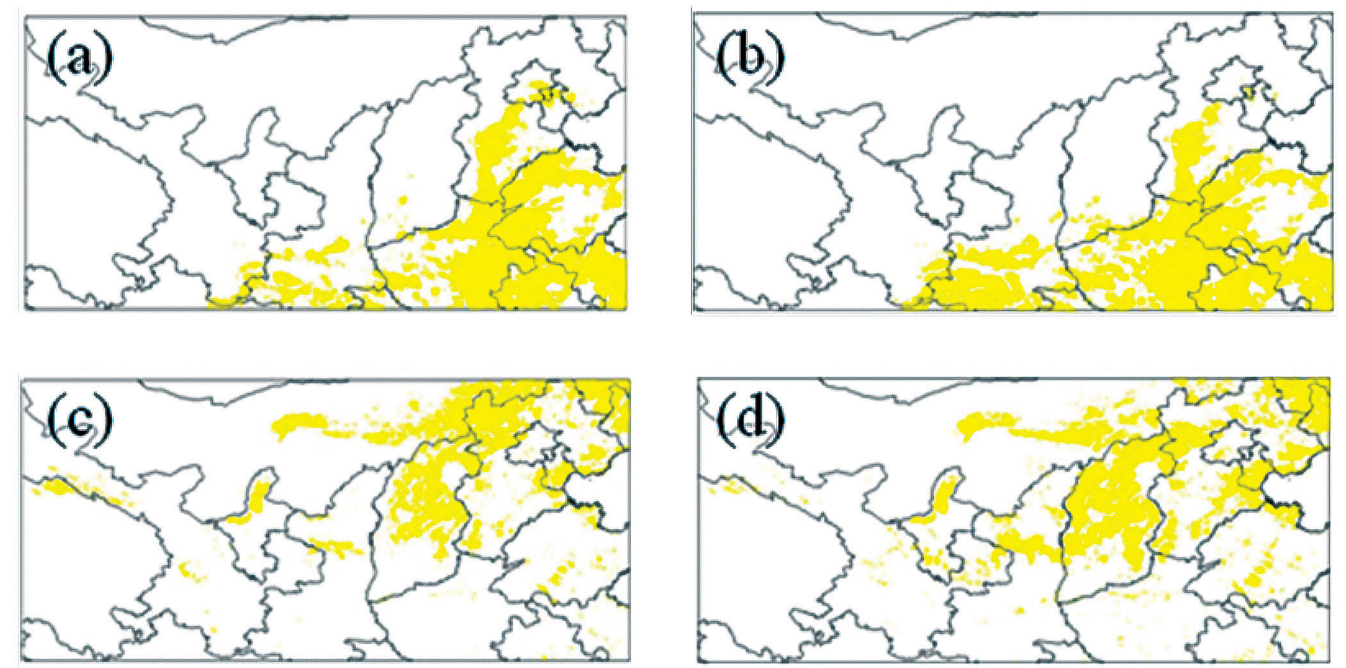

Fig. 7. Wheat and maize distribution in 1999 and 2000 calculated by Approach-3 using NDVI, meteorological data and supervised classification: (a) wheat in 1999; (b) wheat in 2000; (c) maize in 1999; (d) maize in 2000

Table 4. Crop water productivities calculated by Method-1 $\left(10^{9} \mathrm{~m}^{3}\right)$

\begin{tabular}{cccc}
\hline Approaches & Approach-1 & Approach-2 & Approach-3 \\
\hline 1999 & 2287.7 & 1709.8 & 440.9 \\
2000 & 3176.3 & 2645.7 & 828.8 \\
\hline
\end{tabular}

(5) The annual accumulative daily temperature (for temperature values above $8{ }^{\circ} \mathrm{C}$ ) is larger than $2400{ }^{\circ} \mathrm{C}$, and the total precipitation is less than $900 \mathrm{~mm}$;

(6) Maximum NDVI is larger than 0.4;

According to the above conditions for wheat and maize, their spatial distributions in 1999 and 2000 were identified (Fig. 7).

Supervised classification improved the result of identified wheat distribution in a small part of areas in Shanxi and Hebei provinces, which can be proven by comparing the identified results through Approach 1-3 and the wheat distribution result generated using CIESIN data, respectively. This shows that NDVI with meteorological data and supervised classification could accurately identify the whet distribution.

The identified maize areas by Approach-3 (Fig. 7c, d) become similar to the reference map derived from the CIESIN data (Fig. 2b) as a whole due to the decrease of the maize areas in north Inner Mongolia Autonomous Region, Gansu and Ningxia provinces. By comparing the identified results through Approach-2 and Approach-3 to the CIESIN data respectively, it is found that the difference deviation coefficients decreased from 1.76 to 0.17 , which reveals that the supervised classification improved the accuracy of the maize distribution.

\section{Crop water productivity}

Two methods were used to calculate the crop water productivities of wheat and maize: the first method (Method-1) calculated the total crop yield using average crop yield and the basin area; the second method

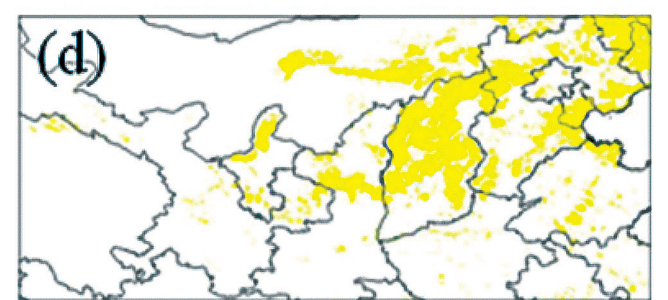

\begin{tabular}{cccc}
\multicolumn{4}{c}{$\left(10^{9} \mathrm{~m}^{3}\right)$} \\
Approaches & Approach-1 & Approach-2 & Approach-3 \\
\hline 1999 & 2624.0 & 1745.0 & 479.5 \\
2000 & 3462.5 & 2705.8 & 851.8 \\
\hline
\end{tabular}



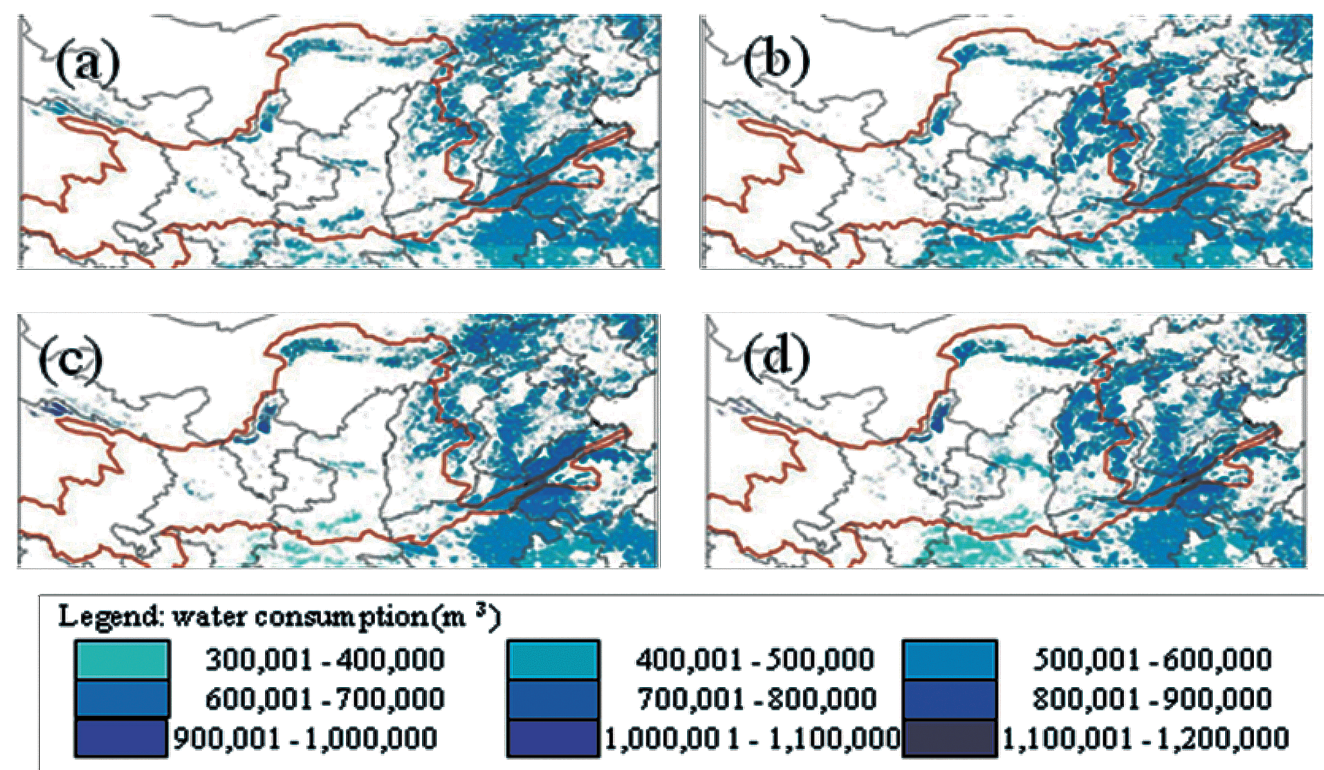

Fig. 8. Crop water productivities in 1999 (a) and 2000(b) calculated by Method-1; crop water productivities in 1999 (c) and 2000(d) calculated by Method-2.

(Method-2) calculated the crop yields in all provinces within the Yellow River basin and then sums up the total crop yield. Fig. 8 shows the crop water productivities of wheat and maize estimated using both methods. The crop water productivities of wheat and maize were calculated using the crop distributions generated through the three approaches (see Table 4 and Table 5).

Table 4 and Table 5 show that the crop water productivities of wheat and maize calculated by Approach-1 and Approach-2 are much larger than that by Approach-3 using either Method-1 or Method-2. The calculated crop water productivities of wheat and maize through Approach-3 are about 440 to $850\left(10^{9} \mathrm{~m}^{3}\right)$. Compared with the reference annual agricultural water productivities (see Table 1) of about 300 to $350\left(10^{9} \mathrm{~m}^{3}\right)$, the crop water productivities of wheat and maize calculated through Approach-1 and Approach-2 are too large, the results calculated through Approach-3 are relatively close to the reference values. In addition, calculated crop water productivities using Method-2 are generally larger than that from Method-1 in both 1999 and 2000, which shows that different crop yield calculation methods have impacts on the final results from crop water productivity simulations.

\section{CONCLUSIONS}

This paper introduces an application of remote sensing data to calculate the crop water productivities of wheat and maize in the Yellow River basin. Three approaches are used to identify the spatial distributions of wheat and maize, that is, 1) application of NDVI, 2) combined application of NDVI and metrological data and 3) combined application of NDVI, metrological data and supervised classification. Through the case study in 1999 and 2000, it is found that crop water productivities of wheat and maize calculated through Approach-1 and
Approach-2 are much larger than that through Approach-3, and the results calculated through Approach-3 are close to the reference values recorded in Yellow River Water Resources Bulletin. This shows that application of remote sensing data in the estimation of crop water productivity can generally give reasonable results, and the different image interpretation methods have great impacts on the accuracy of simulated crop water productivity.

\section{ACKNOWLEGEMENTS}

This research is supported by National Natural Science Foundation of China (Grant No. 41001155) and Kyushu University Research Institute for East Asia Environment.

\section{REFERENCES}

Bastiaanssen, W. G. M., M. Menenti, , R. A. Feddes, A. A. M. Holtslag 1998a A remote sensing surface energy balance algorithm for land (SEBAL): 1. Formulation. J. Hydrol., 212213: $198-212$

Bastiaanssen, W. G. M., H. Pelgrum, J. Wang, Y. Ma, J. F. Moreno, G.J. Roerink, et al., 1998b. A remote sensing surface energy balance algorithm for land (SEBAL): 2. Validation. J. Hydrol., 212-213: 213-229

National Bureau of Statistics of P. R. China 1994 China Statistical Yearbook 1994. China Statistics Press, Beijing (China)

National Bureau of Statistics of P. R. China 1995 China Statistical Yearbook 1995. China Statistics Press, Beijing (China)

National Bureau of Statistics of P. R. China 1996 China Statistical Yearbook 1996. China Statistics Press, Beijing (China)

National Bureau of Statistics of P. R. China 1997 China Statistical Yearbook 1997. China Statistics Press, Beijing (China)

National Bureau of Statistics of P. R. China 1998 China Statistical Yearbook 1998. China Statistics Press, Beijing (China)

National Bureau of Statistics of P. R. China 1999 China Statistical Yearbook 1999. China Statistics Press, Beijing (China)

National Bureau of Statistics of P. R. China 2000 China Statistical 
Yearbook 2000. China Statistics Press, Beijing (China)

CIESIN, China administrative regions GIS data. http://sedac.ciesin. columbia.edu/china/admin/bnd90/bnd90.html

Frolking, S., J. Qiu, S. Boles, X. Xiao, J. Liu, Y. Zhuang, C. Li, et al. 2002 Combining remote sensing and ground census data to develop new maps of the distribution of rice agriculture in China. Global Biogeochem. Cycles, 16: 1-10

Fu, G., S. Chen, C. Liu, D. Shepard 2004 Hydro-climatic trends of the yellow river basin for the last 50 years. Clim. Change, 65: $149-178$

Giordano, M., Z. P. Zhu, X. M. Cai, S. Q. Hong, X. C. Zhang and Y. P. Xue 2004 Water management in the Yellow River Basin: Background, current critical issues and future research needs, Comprehensive Assessment Report 3, Colombo (Sri Lanka)

Guo, Y., Z. Liu, and M. Xie 2009 Vegetation information extraction in the south Qinhai plateau using phenology and supervised classification. Remote Sensing Technology and Application, 24: 223-229 (in Chinese)

Lei, H. and D. Yang 2010 Interannual and seasonal variability in evapotranspiration and energy partitioning over an irrigated cropland in the North China Plain. Agric. For. Meteorol., 150: $581-589$

Li, H., L. Zheng, Y. Lei, C. Li, Z. Liu, S. Zhang 2008 Estimation of water consumption and crop water productivity of winter wheat in North China Plain using remote sensing technology. Agric. Water Manage., 95: 1271-1278

Liu, C. and J. Xia 2004 Water problems and hydrological research in the Yellow River and the Huai and Hai River basins of China. Hydrol. Process., 18: 2197-2210

Mo, X. and S. Liu 2001 Simulating evapotranspiration and photosynthesis of winter wheat over the growing season. Agric. For. Meteorol., 109: 203-222

Oki, T., M. Sato, A. Kawamura, M. Miyake, S. Kanae and K. Musiake
2002 Virtual water trade to Japan and in the world, in: Virtual water trade, Proceedings of the international expert meeting on virtual water trade, Delft, The Netherlands, edited by: Hoekstra A. Y., Research Report Series No. 12

Pereira, L. S., J.M. Goncalves, B. Dong, Z. Mao and S. X. Fang 2007 Assessing basin irrigation and scheduling strategies for saving irrigation water and controlling salinity in the upper Yellow River Basin, China. Agric. Water Manage., 93: 109-122

Sander J. Z. and W. G. M. Bastiaanssen 2004 Review of measured crop water productivity values for irrigated wheat, rice, cotton and maize. Agric Water Management, 69: 115-133

Shao, X. and R. Yan, 2007 Study on the pattern of water requirements of main crops and rainfall in the Yellow River basin Chinese Journal of Agrometeorology, 28: 40-44 (in Chinese)

Wan, H. M, K. Tanaka and S. Ikebuchi 2004 Determination of global soil water content with consideration of the irrigation based on the landsphere SiBUC model. Annual conference of Japan Society of Hydrology and Water Resources., 17 82-83

Xia, J., Z. Wang, G. Wang and G. Tan 2004 The renewability of water resources and its quantification in the Yellow River basin, China. Hydrol. Process., 18: 2327-2336

Zhang, B. Z., S. Z. Kang, L. Zhang, T. S. Du, S. E. Li and X. Y. Yang 2007 Estimation of seasonal crop water consumption in a vineyard using Bowen ratio-energy balance method. Hydrol. Process., 21: 3635-3641

Zheng, H., L. Zhang, C. Liu, Q. Shao and Y. Fukushima 2007 Changes in stream flow regime in headwater catchments of the Yellow River basin since the 1950s. Hydrol. Process., 21 886-893

YRCC (Yellow River Conservancy Commission) 1998-2008 Yellow River Water Resources Bulletin. http://www.yellowriver.gov. cn/other/hhgb 